
cultures

Les cahiers de l'Acedle

\title{
La qualité de l'enseignement des langues-cultures étrangères
}

Quelles priorités pour les étudiant·es à la fin de leur formation en didactique pour l'enseignement d'une langue-culture au secondaire?

\section{Susanne Wokusch}

\section{OpenEdition}

12 Journals

\section{Édition électronique}

URL : http://journals.openedition.org/rdlc/1900

DOI : $10.4000 /$ rdlc. 1900

ISSN : 1958-5772

Éditeur

ACEDLE

Référence électronique

Susanne Wokusch, "La qualité de l'enseignement des langues-cultures étrangères », Recherches en didactique des langues et des cultures [En ligne], 14-2 | 2017, mis en ligne le 15 juin 2017, consulté le 19 avril 2019. URL : http://journals.openedition.org/rdlc/1900; DOI : 10.4000/rdlc.1900

Ce document a été généré automatiquement le 19 avril 2019

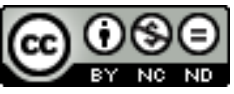

Recherches en didactique des langues et des cultures is licensed under a Creative Commons AttributionNonCommercial-NoDerivatives 4.0 International License 


\section{La qualité de l'enseignement des langues-cultures étrangères}

Quelles priorités pour les étudiant·ess à la fin de leur formation en didactique pour l'enseignement d'une langue-culture au secondaire ? ${ }^{1}$

\section{Susanne Wokusch}

\section{Introduction}

\section{Vue d'ensemble}

1 Dans le contexte de la formation des enseignante's de langues-cultures étrangères (LCE) à l'école secondaire, nous posons d'abord un cadre de référence de critères de qualité de l'enseignement d'une LCE afin d'illustrer les visées de la formation pour les étudiant···s. Ces critères ont servi de base à un travail de réflexion d'une cohorte d'étudiant·es invitée's à se positionner par rapport à ces critères et à les classer en fonction de la perception de leur priorité. Ce travail de réflexion constitue le corpus que nous analysons par la suite, d'abord pour la cohorte entière ; dans un deuxième temps, nous distinguons entre le secondaire 1 et le secondaire 2 et dans un troisième temps, nous comparons les étudiant·ess se préparant à l'enseignement de l'allemand vs. l'enseignement de l'anglais.

\section{Contextualisation}

On l'a souvent relevé, la formation à l'enseignement présente une particularité dans le sens où les personnes en formation ont une fine connaissance de la profession depuis leur perspective d'apprenantee, ayant passé par ce que l'on appelle depuis l'étude de Lortie (1975) un "apprentissage par observation». Chaque future enseignante a vécu l'enseignement d'une LCE en tant qu'apprenante et suivant son parcours d'apprentissage naturel et / ou institutionnel, il / elle a développé des convictions, croyances, représentations ou théories subjectives par rapport aux meilleures manières d'enseigner / apprendre une langue-culture étrangère ; ces aspects sont étudiés dans le contexte de la 
pensée enseignante (cf. Woods, 1996; Cambra Giné, 2003, Causa 2012, Starkey-Perret, 2013 ; pour le contexte suisse-romand, Wokusch \& Sieber, 2000). Il est clair que ces représentations peuvent exercer une forte influence sur les pratiques d'enseignement et doivent donc être prises en compte par la formation en didactique.

Concernant le développement des compétences en didactique des enseignante-s, la formation peut avoir des effets limités. Beacco (2007) oppose la « didactique des didacticiens » à celle des enseignants (op. cit. : 40); il explique que - sur la base d'une analyse de moyens d'enseignement parus en France à la fin du dernier siècle - l'on peut « postuler l'existence d'une stratégie méthodologique partagée, qui n'est certes pas l'approche communicative 'forte' » $(2007: 48)$ et correspond donc à la «didactique des enseignants ». Cette "approche globaliste » n'est, selon lui, pas enseignée dans les institutions de formation :

[elle] agit comme un ensemble de représentations (...) et elle constitue ainsi un cadre où viennent se modeler les attentes éducatives d'apprenants partageant ces représentations et pratiques ordinaires de l'enseignement (Beacco, $2007: 44$ ).

Comme cette approche n'est pas enseignée dans les institutions de formation, nous pouvons évoquer «l'apprentissage par observation» comme un des canaux de transmission. Beacco semble partager cette hypothèse :

... elle [l'approche globaliste] semble héritée comme par tradition. Son mode de reproduction opère avant toute formation professionnelle des enseignants : dans les classes de langue, où les futurs enseignants sont d'abord élèves, ils y sont très probablement exposés pendant plusieurs années (...) en tant qu'apprenants de langues (Beacco, $2007: 48$ ).

Dans ses réflexions sur la notion de répertoire didactique, Causa (2012) mentionne également l'expérience des modèles d'enseignante's observée's comme une des sources du répertoire didactique en développement des jeunes enseignant-ess de langues-cultures.

Nous rejoignons la caractérisation que Beacco (2007) a fait de l'enseignement dans le contexte français. Les observations personnelles de l'auteure confirment l'existence d'une manière particulière d'enseigner les langues-cultures très présente en Suisse romande pouvant également être observée chez beaucoup d'étudiante-s dès leurs débuts en formation. Une enquête auprès des enseignante-s praticiennes formatrices et praticiens formateurs accompagnant les stages des futurees enseignantees du secondaire 1 et 2 à la Haute École pédagogique du canton de Vaud (HEP VD) en Suisse, conduite en 2014², permet de caractériser les pratiques d'enseignement locales actuelles comme un enseignement orienté vers la communication (cf. Littlewood, 2014), accordant beaucoup de valeur au travail explicite; dans cette conception, l'enseignement semble plus préparer l'utilisation réelle de la langue-culture enseignée que de la mettre en œuvre à l'école.

5 Pour la formation à l'enseignement, le défi est alors majeur. En effet, comment surmonter la distance entre les approches d'enseignement transmises par observation, par «filiation» entre les différentes générations d'enseignante's et les conceptions en didactique, s'orientant sur «l'état de l'art» en didactique, se fondant dans toute la mesure du possible sur la recherche et des résultats vérifiés? Et en amont de cela, comment la formation en didactique est-elle reçue par les étudiant-e's, qu'est-ce qu'elles / ils retiennent de la formation? Et quelles priorités voient-elles / ils pour leurs pratiques d'enseignement? Ce questionnement nous amène à nous intéresser à la pensée enseignante (teacher cognition, cf. notamment Borg, 2006), ayant récemment fait l'objet du numéro 56 de la revue Le français dans le monde. Recherches et applications. (cf. notamment les contributions de Woods \& Knoerr ; Barcelos ; Cicurel et al. 2014). Dans le contexte de la 
présente recherche, nous nous intéressons particulièrement à la pensée des enseignant·e·s avant leur entrée en fonction; de plus, cet intérêt de recherche se place directement au service de la formation dans la mesure où nous évaluerons également un outil de formation, une tâche de réflexion personnelle. Cette visée confère un caractère de recherche-action à notre travail.

\section{Problématique}

\section{Viser un enseignement des langues-cultures étrangères de qualité}

6 Partant de l'idée que le désir de devenir ou le cas échéant, être, un·e bon.ne enseignant·e (de langue-culture étrangère) motive les étudiante-s tandis que la volonté d'y contribuer habite les formatrices et formateurs, il nous semble indispensable d'expliciter en quoi un enseignement de qualité peut consister afin de disposer d'un point de référence commun pour les étudiante's et les intervenante's en didactique. Cela paraît d'autant plus important qu'il peut être tentant d'interpréter certains aspects du Cadre européen commun de référence pour les langues (2001), des suggestions contenues dans des moyens d'enseignement ou dans les plans d'études, ou encore des pratiques courantes (la "didactique des enseignante-s»; Beacco, 2007) comme autant de prescriptions ou de modèles à suivre, pensant garantir ainsi un enseignement de qualité. Ce serait également oublier le rôle central de l'enseignantee en tant que médiatrice ou médiateur ouvrant l'accès à l'apprentissage de la langue-culture enseignée à un groupe spécifique d'apprenante-s dans toute sa diversité (cf. les travaux de Hattie, 2009 et 2012 abordant de manière transversale le rôle décisif de l'enseignant·e pour les apprentissages).

Opérationnaliser les objectifs de la formation en explicitant les caractéristiques d'un enseignement des LCE de qualité nous donnera également un outil pour situer les pratiques des étudiante's par rapport à des repères spécifiques et non seulement par rapport à un référentiel de compétences générales de l'enseignant·e. Comme déjà évoqué, dans le contexte de ce travail, nous nous intéressons aux effets subjectifs de la formation en didactique sur les représentations en amont des pratiques d'enseignement proprement dites. Nous rejoignons en cela l'appréciation de Barcelos (2014) concernant l'influence forte des croyances sur les pratiques des enseignant-e's. En effet, nous sommes d'avis que plus nous réussissons à atteindre les représentations profondes des étudiant·e's durant la formation, plus la probabilité de les modifier est grande. Cela augmenterait aussi la probabilité que les pratiques des enseignante's en formation se fondent sur de nouvelles bases.

\section{Des critères pour la qualité de l'enseignement}

8 L'indicateur de la qualité de l'enseignement étant en premier lieu l'efficacité de l'enseignement se manifestant dans les progrès des apprentissages, il convient de se référer aux compétences attendues par les apprenante-s. Pour déterminer un dénominateur minimal commun pour l'enseignement des langues-cultures étrangères à tous les niveaux de la scolarité à travers l'Europe, on peut affirmer que l'on vise aujourd'hui une compétence de communication fonctionnelle partielle développée à un niveau déterminé (par contraste, par ex., à la maîtrise d'un ensemble de règles grammaticales et d'un vocabulaire). 
9 Nous avons donc entrepris d'identifier des critères de qualité pour l'enseignement des LCE en nous libérant, dans toute la mesure du possible, de considérations théoriques voire idéologiques et en privilégiant des travaux empiriques. Cette démarche ouverte nous semble appropriée pour laisser de la place pour la pensée critique et favoriser une posture réflexive chez les enseignant·ess en formation et en fonction. Nous avons présenté le processus d'élaboration et les critères identifiés dans Wokusch (2013) en prenant en compte les aspects pédagogiques et didactiques, correspondant à la double fonction de l'enseignant·e : gérer la classe ainsi que sélectionner, structurer et gérer les contenus (cf. Altet, 2001). Ce travail s'appuie sur des travaux en sciences de l'éducation concernant la qualité de l'enseignement et l'effet de l'enseignantee, complétés par des résultats d'enquête sur l'efficacité de l'enseignement des langues; cette démarche nous a permis de proposer un ensemble de caractéristiques d'un enseignement des langues-cultures de qualité pouvant servir de référence aux étudiant·e-s. Précisons encore que ces critères ont été formulés pour toutes les langues-cultures étrangères enseignées en Suisse romande : l'allemand, l'anglais, l'italien et l'espagnol. Cela correspond également à l'approche intégrative de la formation en didactique des LCE pratiquée à la HEP VD qui réunit les étudiante-s de toutes les didactiques des LCE pour certaines parties de la formation ${ }^{3}$.

Dans un deuxième temps, nous avons comparé ces critères à des données qualitatives obtenues à travers des entretiens avec des enseignantees de LCE en formation et en fonction, entretiens centrés entre autres autour des valeurs sous-jacentes à la prise de décision dans l'enseignement. Cette modeste comparaison a permis de constater une bonne convergence des caractéristiques d'un bon enseignement des LCE entre les deux types de démarches et peut être considérée comme une validation rudimentaire des critères de qualité.

11 Ci-dessous, nous présentons les 13 critères de qualité pour l'enseignement des LCE, organisés en cinq thématiques; le premier groupe (Présence et rôle de la langue-culture) est spécifique à l'enseignement des LCE visant la communication et engage également l'enseignant·e. La deuxième thématique (Droit à l'erreur) est étroitement liée au premier groupe. Les thématiques trois et quatre (Enseignement / apprentissage et rôle des apprenante's; Types d'activités et structuration des leçons) touchent aux démarches de didactique des LCE proprement dites tandis que la thématique cinq ainsi que le critère 4.11 relèvent de la gestion de la classe (aspects transversaux). 
Tableau 1 - 13 critères de qualité pour l'enseignement des LCE (Wokusch, 2013)

\section{Présence et rôle de la langue-culture}

1. L'enseignante a une maîtrise de la langue enseignée lui permettant d'être à l'aise et de communiquer spontanément en classe, par ex. pour faire face à des imprévus. L'enseignant·e montre par ses attitudes qu'elle/il est engagéee dans l'apprentissage de la langue-culture avec ses élèves.

2. L'enseignement est enrichi de documents authentiques et propose de nombreuses possibilités de contact avec la langue-culture enseignée. La dimension interculturelle et culturelle est régulièrement présente.

3. La langue enseignée est le moyen de communication principal de l'enseignement; la langue de scolarisation est utilisée si nécessaire. Lors des échanges avec les élèves, l'enseignant·e veille à maintenir l'interaction au-delà du simple schéma « question de l'enseignant·e - réponse de l'élève » pour favoriser un apprentissage en situation de communication.

\section{Droit à l'erreur}

4. Tant l'enseignante que les élèves ont le droit de faire des erreurs; les erreurs sont considérées comme naturelles et incontournables. Pour un meilleur apprentissage, l'enseignant·e donne l'opportunité aux élèves de s'auto-corriger (et peut montrer l'exemple).

\section{Enseignement / apprentissage et rôle des élèves}

5. L'enseignant.e suit les processus d'apprentissage de ses élèves et connaît les forces et les faiblesses de chacune ; dans toute la mesure du possible, elle/il intègre cette dimension dans sa préparation afin de soutenir les élèves par des mesures de différenciation.

6. L'enseignement est conçu en fonction du plan d'études mais il est adapté aux élèves, en fonction de leurs rythmes, capacités, intérêts. Quand elle/il sollicite des élèves, l'enseignant·e laisse suffisamment de temps de réflexion avant d'intervenir.

7. Au niveau des thématiques et contenus abordés, les intérêts des élèves sont pris en compte.

8. Les élèves sont en activité pendant la plus grande partie de la leçon et ont régulièrement des opportunités d'utiliser la langue en production; l'enseignante planifie et guide les activités mais les élèves disposent d'une marge de manœuvre pour effectuer leur travail de manière autonome.

Types d'activités et structuration des leçons

9. L'enseignement présente des opportunités d'apprentissage implicite et explicite; le travail des formes de la langue ne se limite pas à la grammaire mais comprend également des aspects textuels et socio-culturels.

10. Il y a suffisamment d'opportunités pour entraîner, consolider et stabiliser les apprentissages afin d'automatiser certains éléments.

11. Les leçons sont structurées de manière claire et cohérente; les élèves savent à quels moments elles/ils sont censée's faire quoi et savent aussi pourquoi.

Gestion de la classe et climat de classe

12. La gestion de classe est basée sur des règles claires afin de permettre une utilisation optimale du temps pour l'apprentissage.

13. Le climat de classe est basé sur la confiance ; l'ambiance est détendue et l'humour a sa place.

12 Une fois que nous disposons de ces critères de qualité, il est possible de situer les enseignant·e's en formation par rapport à cette référence. Comme expliqué auparavant, nous avons opté pour un accès indirect aux pratiques d'enseignement des étudiant·e·s, en nous intéressant à leur positionnement personnel par rapport à ces critères. 


\section{Un retour sur l'impact de la formation à travers les perceptions des étudiant $\cdot e \cdot s$}

13 La formation à l'enseignement des LCE à la Haute Ecole pédagogique du Canton de Vaud se caractérise par une séparation entre la formation pratique (stages dans des établissements scolaires accompagnés et certifiés par des enseignante•s praticiennes formatrices et praticiens formateurs) d'une part, et la formation au sein de la HEP VD d'autre part, divisée à son tour entre les aspects transversaux (sciences de l'éducation) et la formation didactique proprement dite. Cette organisation cloisonnée décomposant le caractère complexe de l'enseignement (et qui est à notre connaissance la règle dans les formations à l'enseignement) va de pair avec l'académisation des formations à l'enseignement. A cela s'ajoute une augmentation considérable du nombre d'étudiantees en formation et un nombre limité de crédits à disposition pour la formation en didactique (12 crédits par discipline d'enseignement au secondaire à la HEP VD). Dans ces conditions, il est difficile de trouver un espace propice pour travailler avec les étudiante's sur le lien théorie-pratique, la pratique réflexive et leurs représentations et convictions concernant l'enseignement / apprentissage des LCE.

14 Afin de contourner ces contraintes, nous avons opté pour une démarche individualisée, sous forme de réflexions personnelles à conduire par chaque étudiantee, sur la base de consignes précises liées aux contenus abordés dans le cours de didactique assumée par l'auteure. Ce travail est un prérequis à la certification du dernier module en didactique ; il est donc obligatoire. La forme que prennent ces réflexions est laissée au choix de l'étudiant·e. Le seul contrôle effectué est la vérification que le travail de réflexion a été fait. Il n'y a donc pas d'évaluation, ce qui garantit la liberté de la pensée des étudiant·•·s. Le but premier de cette activité est de favoriser une « rencontre » des contenus du cours avec les théories implicites, convictions et croyances de l'étudiant·e et d'approfondir ainsi l'impact de l'enseignement en didactique. Dans le cadre du présent travail, nous nous sommes intéressée à l'évaluation de la pertinence pour leur pratique des critères de qualité présentés ci-dessus par une promotion d'étudiant·e's de notre institution, en fin de formation en didactique des LCE (promotion 2014 - 2015, semestre de printemps 2015, formation en didactique consistant en 2 modules, à 6 crédits par module).

15 La consigne pour la réflexion personnelle des étudiante's en lien avec la qualité de l'enseignement est la dernière des six demandées et comprend deux volets : le premier consiste à classer les 13 critères selon leur importance aux yeux de l'étudiante en notant des interrogations ou résistances; le deuxième volet demande à l'étudiantee de faire l'inventaire des critères qu'elle/il pense déjà remplir dans son enseignement et d'élaborer quelques pistes pour son enseignement futur, en fonction de son classement personnel.

16 Il est évident que le classement de ces caractéristiques selon leur importance est une tâche très difficile et dont la pertinence peut être questionnée. En effet, comme décrit plus haut, pour mieux les structurer, nous avons regroupé les 13 critères identifiés en cinq thématiques et certains critères contiennent plusieurs énoncés portant sur des caractéristiques d'ordre similaire. Dans l'ensemble, le résultat est complexe et dense, témoignant du souci d'intégrer un maximum d'éléments dans une forme compacte.

17 Néanmoins, dans le contexte de formation, l'activité décrite est proposée pour deux raisons : premièrement, pour attribuer un rang à chaque critère, l'étudiant·e doit $\mathrm{y}$ réfléchir de manière profonde, en le comparant avec d'autres; deuxièmement, le 
classement des étudiante's peut refléter leurs préoccupations à ce stade de leur formation, ce qui peut être précieux pour ajuster le dispositif. Les données issues d'un travail de validation d'un cours présentent évidemment des problèmes et peuvent être influencées par cet objectif; à cela s'ajoute un biais typique pour ce genre de données correspondant à des déclarations et non nécessairement à des attitudes profondes et à des pratiques réelles. Toutefois, les classements de priorités que les étudiant·e·s effectuent parmi les critères de qualité peuvent certainement être considérés comme des orientations stratégiques structurant le développement de leur répertoire didactique que nous définissons avec Causa (2012:15) comme " (...) ensemble de savoirs, savoir-faire et savoir-être pédagogiques dont dispose l'enseignant pour transmettre la langue cible à un public donné et dans un contexte précis.»

En raison du corpus relativement important (75 travaux, cf. la description de la démarche plus bas) et l'objectif d'un retour sur la perception des critères de qualité de l'enseignement par l'ensemble des étudiante's, notre perspective sera globale. Nous nous intéresserons donc à des tendances générales et ne procéderons pas à des études de cas individuels.

\section{Questions de recherche}

19 Notre intérêt de recherche porte, d'une part, sur la perception des critères de qualité en général et vise, d'autre part, à investiguer l'influence des facteurs «filière d'enseignement visée» et «langue-culture enseignée»; ces informations sont particulièrement importantes pour la conception intégrative, partiellement commune de notre formation afin de ne pas passer à côté d'obstacles potentiels pour notre approche intégrative.

20 Par conséquent, l'analyse sera guidée par trois questions de recherche. La première concernant la population étudiante de manière globale, la deuxième visant une différenciation par filière de formation, la troisième cherchant à identifier d'éventuelles différences entre les langues les plus enseignées : l'allemand (comme langue nationale en Suisse) et l'anglais (pour plus de détails cf. ci-dessous la description de la démarche).

21 Voici les questions :

1. Est-ce que l'on peut déceler des priorités ou des préoccupations générales chez les étudiante-s en didactique des langues-cultures au terme de leur formation en didactique? 2. Existe-t-il des différences entre les priorités ou préoccupations des étudiante-s en fonction de leur filière de formation (secondaire 1 vs. secondaire 2) et de quelle nature sont-elles?

3. Existe-il des différences entre les priorités ou préoccupations des étudiante-s en fonction de la langue enseignée (allemand vs. anglais) et de quelle nature sont-elles?

\section{Hypothèses}

Aux trois questions de recherche correspondent des hypothèses que nous présenterons question par question en les étayant, le cas échéant. Précisons que ces hypothèses font écho - du moins en partie - aux attentes ou intuitions qui nous ont motivée pour cette étude. De manière générale, pour l'enseignement des langues-cultures étrangères, trois facteurs sont au premier plan: la gestion de la classe et la gestion des contenus (les 
fonctions pédagogique et didactique, cf. Altet, 2001) ainsi que la gestion des langues, à savoir l'alternance entre la langue-culture enseignée et la langue de scolarisation ${ }^{4}$.

\section{Priorités ou préoccupations générales en fin de formation}

Concernant les trois facteurs mentionnés, il suffit d'une revue de la littérature même rapide et superficielle pour constater que la gestion de la classe constitue une préoccupation bien présente non seulement pour les débuts dans l'enseignement mais bien au-delà. Des publications comme Muller (2008) contenant la notion de "survie " dans le titre ou de Richoz (2009) abordant la gestion de classes ou d'élèves difficiles (les deux titres déjà dans la $5^{\mathrm{e}}$ édition) indiquent l'importance de cette dimension de l'enseignement. Pour illustrer ceci, Martineau, Gauthier et Desbiens notent, en référence à un travail de Carter et Doyle (1987) que :

(...) pour la plupart des enseignants, la gestion des apprentissages prend souvent l'allure d'un épiphénomène dans la classe tellement les contraintes de gestion de classe sont centrales. (Martineau, Gauthier et Desbiens, $1999: 469$ )

Dans son étude de 2012, Griffiths confirme ces préoccupations pour ses informateurs enseignante's de langue non débutante's en Turquie pour qui la gestion de la classe (ou du groupe d'apprenantees) est plus importante que le contenu (qui vient en deuxième position) ou encore des questions de méthodologie qui occupent seulement la cinquième place sur six catégories en tout.

$24 \mathrm{Au}$ vu de ces constats, nous nous attendons à ce que les enseignante's en formation, novices pour la plupart d'entre elles/eux (mis à part quelques exceptions, par ex. des enseignanters se formant à une discipline supplémentaire) indiquent également les critères liés à la gestion de la classe comme une priorité.

Concernant la gestion des contenus, le travail didactique proprement dit, nous supposons qu'il passe au deuxième plan. Quant à la gestion des langues, à savoir l'utilisation de la langue-culture étrangère, nous pouvons également penser qu'elle n'est pas une préoccupation prioritaire tant que la gestion de la classe n'est pas routinisée.

\section{Différences concernant les priorités des étudiant $\cdot e \cdot s$ de la filière de formation au secondaire 1 versus secondaire 2}

Comme les classes de la scolarité obligatoire (secondaire 1) sont bien plus hétérogènes (et les enseignante's en formation souvent plus jeunes que leurs collègues du secondaire 2, dû à des parcours académiques plus courts), nous pouvons supposer que les préoccupations concernant la gestion de la classe seront plus importantes encore pour la filière secondaire 1 que pour la filière secondaire 2 .

Concernant la gestion de la matière, nous ne nous attendons pas à trouver des différences marquées entre étudiant·es des deux filières.

Pour ce qui est du rôle et de la place de la langue-culture dans l'enseignement, il faut prendre en compte le fait que les exigences en termes de niveaux de référence divergent entre les deux filières : niveau $\mathrm{C} 1$ pour le secondaire $1 \mathrm{vs}$. niveau $\mathrm{C} 2$ pour le secondaire $2^{5}$. Ces exigences différenciées s'expliquent par le niveau (attendu) des apprenante-s: débutant au secondaire 1 , plus avancé au secondaire $2^{6}$. Fort de ces constats, nous pouvons penser que les conditions pour utiliser la langue-culture comme langue 
d'enseignement principale sont moins favorables au secondaire 1 (maitrise de langue par l'enseignantee et les apprenante-s, hétérogénéité des classes, besoin de cadrage des apprenant·ess plus fort); à cela s'ajoute la possibilité accrue que les enseignante-es se trouvent en situation d'insécurité linguistique (cf. Roussi, 2009) en raison de leurs compétences éventuellement moins développées en LCE. Tandis qu'au secondaire 2, les conditions pour l'utilisation de la langue enseignée semblent bonnes: la maîtrise de langue par l'enseignant·e est (censée être) élevée, les apprenant·e·s s'approchent soit d'un niveau intermédiaire, soit avancent rapidement, les classes sont plus homogènes (après une sélection des apprenante-s), des contenus relativement complexes peuvent être traités en langue étrangère. Nous faisons donc l'hypothèse que les futur'e-s enseignant·e·s du secondaire 2 attachent plus d'importance à l'utilisation de la langue enseignée en classe que leurs collègues du secondaire 1 .

\section{Différences entre les priorités ou préoccupations des futur·e·s enseignant $\cdot e \cdot s$ d'allemand versus anglais}

La troisième question de recherche prend son origine dans notre expérience et des échanges avec des formatrices et formateurs en charge des différentes didactiques des langues conduisant à l'impression que la conception de « l'objet d'enseignement » langueculture diffère entre les future-s enseignante-s des différentes LCE et que cela peut se traduire dans des priorités différentes. Ces différences pourraient se manifester, d'une part, dans le choix de démarches didactiques mais également dans le choix de la langue d'enseignement; en effet, si l'on considère la langue comme un objet d'apprentissage que l'on met à distance pour l'étudier, on aura recours à des activités à caractère plutôt métalinguistique et l'on pourra conduire son enseignement du moins en partie dans la langue de scolarisation, de manière similaire à la méthode traditionnelle. A l'inverse, du moment où l'on considère la langue comme un outil de communication et un savoir-faire, l'on privilégiera des activités amenant les apprenante-s à utiliser la langue-culture tout en recourant dans une grande mesure à la langue enseignée comme langue de l'enseignement. Pour des raisons de nombre d'étudiante's (cf. la description de la population de l'étude), nous nous limitons pour cette analyse aux deux langues les plus enseignées (allemand et l'anglais), langues obligatoires pour tous les apprenante's en Suisse romande, en excluant l'italien et l'espagnol, langues apprises comme options. Notre hypothèse est la suivante : en lien avec la culture d'enseignement locale ${ }^{7}$ et la perception de la structure des langues concernées, les enseignantees d'allemand ont plus tendance à considérer la langue comme un objet, tendance qui se manifestera dans des priorités concernant le choix des activités et une moindre importance accordée à l'utilisation de l'allemand comme langue de la classe. Nous postulons une tendance inverse pour les future's enseignante's d'anglais. Par rapport à l'approche intégrative propre à notre formation, de telles différences seraient importantes à connaître pour pouvoir les prendre en compte.

\section{Démarche}

Dans ce qui suit, nous nous intéressons exclusivement au classement des critères de qualité selon leur importance perçue par les étudiante-s, sans prendre en compte les autres volets de la tâche de réflexion. Précisons qu'il s'agit de la volée de formation 
2014-15 de 75 étudiant·e·s. Les futur·e·s enseignant·e·s du secondaire 1 (apprenant·e·s de 12 à 15 ans environ) entrent dans la HEP VD avec un bachelor académique comme exigence minimale dans la discipline pour laquelle elles/ils se forment. Leurs collègues du secondaire 2 (apprenant·e's de 16 à 19 ans environ) sont titulaires d'une maîtrise académique dans la LCE concernée. Nous avons déjà évoqué le niveau de maîtrise de la langue exigé comme prérequis à la formation pour l'enseignement : $\mathrm{C} 1$ pour le secondaire 1 et $\mathrm{C} 2$ pour le secondaire 2 . Nous ne tiendrons pas compte de caractéristiques personnelles des étudiant·e's qui diffèrent au niveau de leur biographie linguistique, de leur expérience, de leur âge etc. Par manque de données, nous ne pouvons pas non plus tenir compte de la modalité de leur stage d'enseignement (en responsabilité ou accompagné par une praticienne formatrice ou un praticien formateur, dans la classe de ces derniers).

31 En raison de la forme libre que prennent les réflexions des étudiant·es, nous avons procédé à une analyse de contenu en extrayant les classifications présentées en général sous forme de texte suivi ou de tableaux; ces classements ont été reportés dans un tableau pour traiter les données (filtrage, comptage, calcul de pourcentages au moyen du logiciel Microsoft Excel). Dans un premier temps, nous ne différencierons pas entre les filières de formation (secondaire 1 ou 2) ni entre les différentes langues-cultures (au secondaire 1: allemand, anglais, italien; au secondaire 2 : allemand, anglais, italien, espagnol). Pour présenter les résultats de la manière la plus lisible possible, nous avons regroupé les 13 rangs possibles en considérant que les rangs 1 à 4 correspondaient à la valeur « très important ", les rangs 5 à 9 à la valeur « important » et les rangs 10 à 13 à la valeur «moins important» Pour des raisons de simplicité et de comparabilité, tous les chiffres sont exprimés en pourcents même si le nombre d'informatrices et d'informateurs est réduit - il s'agit alors de garder ce fait en mémoire et de ne pas généraliser les résultats qui peuvent être spécifiques aux étudiant·es composant cette cohorte. Malgré les résultats chiffrés, il s'agit d'une analyse qualitative sans prétention à une quelconque généralisabilité.

Comme indiqué ci-dessus, les données exploitées ici ne sont pas des données prises en premier lieu à des fins de recherche mais des données issues de travaux d'étudiant·e·s. C'est pour cela que l'analyse fournira au plus des tendances. Les travaux des étudiant·e's étant nominatifs, nous avons traité le corpus seulement une fois la formation en didactique terminée pour éviter tout biais lors de la certification finale des étudiant·e·s.

La promotion 2014-2015 des étudiant·e's en formation à l'enseignement d'une LCE au secondaire 1 et 2 à la HEP VD se compose de la manière suivante : 25 étudiant·es en formation pour l'enseignement de l'allemand (13 pour le secondaire 1, 12 pour le secondaire 2) ; 36 étudiant·e's en formation pour l'enseignement de l'anglais (17 pour le secondaire 1, 19 pour le secondaire 2), 11 étudiant·e's en formation pour l'enseignement de l'italien (8 pour le secondaire 1, 3 pour le secondaire 2) et 3 étudiant·es en formation pour l'enseignement de l'espagnol (secondaire 2 uniquement).

\section{Résultats}

\section{Classement général des critères}

Dans l'ensemble, la consigne a été bien suivie : seulement 6 étudiant·es (4,5\%) n'ont pas classé les 13 critères et aucun'e étudiant·e n'a contesté la pertinence des critères. Quinze 
étudiant·es ont déclaré être dans l'incapacité d'établir une hiérarchie entre les critères signalant, par exemple, que les caractéristiques représentaient "l'écosystème d'un bon enseignement ", qu'il n'y avait "pas de critère qui prévaut sur les autres » ou encore qu'ils étaient « tous imbriqués et dépendants ». D'autres n'ont pas classé tous les critères ou ont classé les cinq groupes de critères, ce qui fait que le nombre de jeux de données valables pour l'analyse varie entre 63 et 67 , selon le critère.

Le tableau 2a ci-dessous présente les classements de rang pour les 13 critères de qualité, exprimés en pourcentage. Pour rappel, nous assimilons les rangs 1 à 4 à "très important ", 5 à 9 à «important » et 10 à 13 à «moins important ». Pour les calculs de pourcentages, nous avons exclu les valeurs manquantes et les travaux ne respectant pas la consigne. Le classement 0 a été attribué pour les travaux n'établissant pas de hiérarchie entre les critères. Les deux dernières lignes du tableau représentent les regroupements des valeurs positives («très important » et «important», désigné par «Cumul 1 à 9 »); pour la désignation «Cumul 0 à 9 » (deuxième ligne), nous avons ajouté la classification 0 signifiant une priorité égale pour toutes les caractéristiques d'un enseignement de qualité.

Tableau 2a : Classement général des critères $(n=69)$

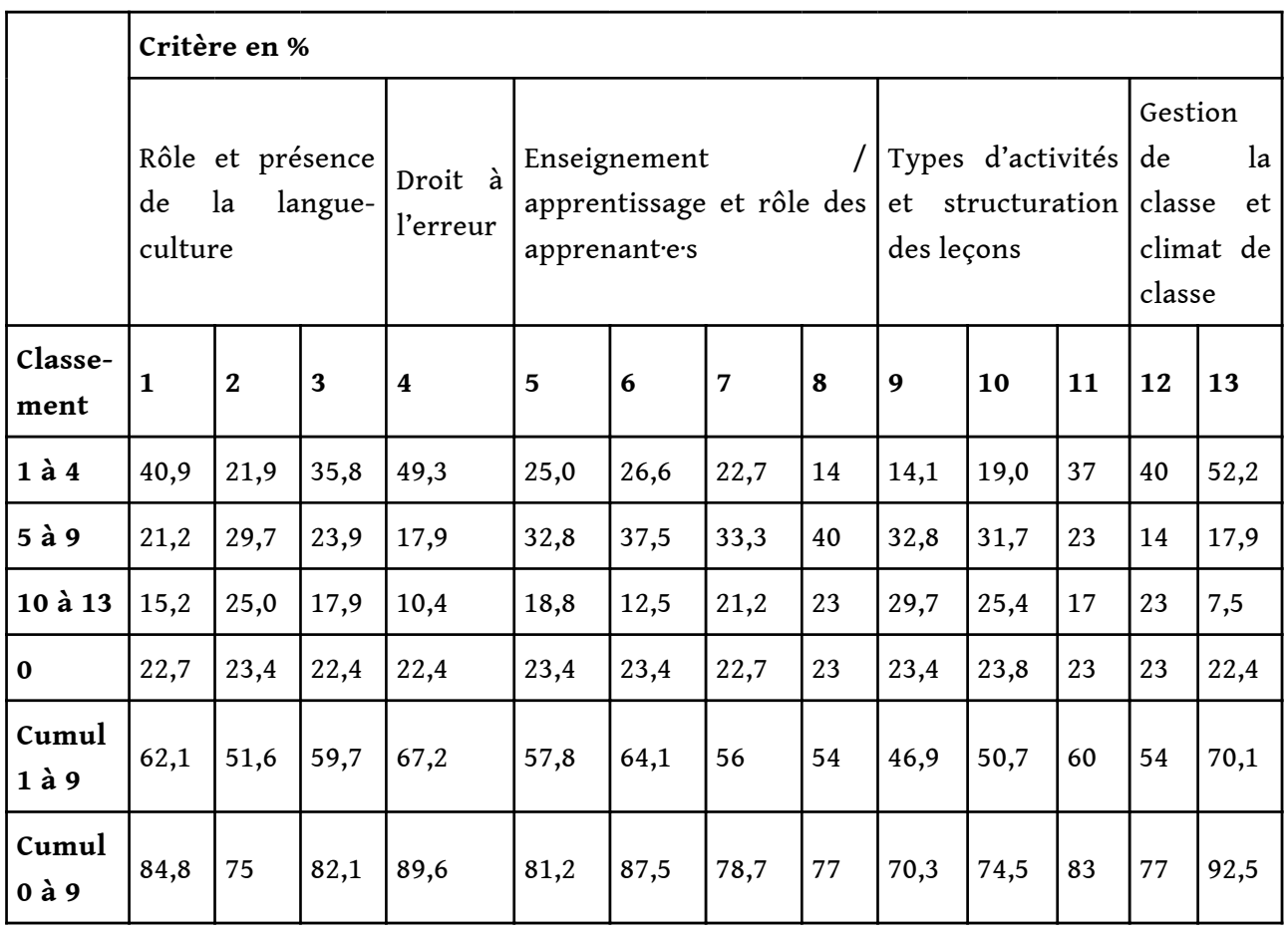

Dans un premier temps, nous avons cherché à établir une classification générale de la perception de l'importance des critères par les étudiantees, sur la base du cumul 0 à 9 , représentée dans le tableau 1a ci-dessous.

Tableau 2b Classement des critères par rang (=69)

\begin{tabular}{|l|l|l|}
\hline Rang & Critère (mots clé et no) & $\begin{array}{l}\text { Valeur en } \\
\%\end{array}$ \\
\hline
\end{tabular}




\begin{tabular}{|l|l|l|}
\hline 1 & Climat de classe, ambiance (13) & 92,5 \\
\hline 2 & Droit à l'erreur (4) & 89,6 \\
\hline 3 & Alignement curriculaire de l'enseignement, adaptation aux élèves (6) & 87,5 \\
\hline 4 & Maîtrise de la langue, engagement de l'enseignant·e (1) & 84,8 \\
\hline 5 & Structuration des leçons (11) & 83 \\
\hline 6 & Utilisation de la langue enseignée en classe (3) & 82,1 \\
\hline 7 & Suivi des apprentissages (5) & 81,2 \\
\hline 8 & Prise en compte de l'intérêt des élèves (7) & 78,7 \\
\hline 9 & Activités et autonomie des élèves (8) et Gestion de la classe (12) & 77 \\
\hline 10 & Documents authentiques, contacts, dimension (inter)culturelle (10) & 75 \\
\hline 11 & Entraînement et stabilisation des apprentissages (10) & 74,5 \\
\hline 12 & $\begin{array}{l}\text { Opportunités d'apprentissage implicite et explicite ; formes au sens large } \\
(9)\end{array}$ & 70,3 \\
\hline
\end{tabular}

Comme nous pouvons le constater, chaque critère correspond à un pourcentage dépassant les deux tiers; tous les critères peuvent alors être considérés comme importants aux yeux des étudiante-s. Toutefois, on peut distinguer deux groupes, le premier étant apprécié à plus de $80 \%$ (rangs 1 à 7) et le deuxième en dessous de $80 \%$ (rangs 8 à 12). A y regarder de plus près, nous pouvons observer que les sept premiers rangs constituent en quelque sorte un minimum de "survie » en classe et nous pouvons supposer que l'enseignante dépend dans une certaine mesure de l'ambiance de la classe. Nous pouvons y voir le portrait d'une enseignante pour qui la plupart des aspects didactiques passent encore au deuxième plan (à l'exception du droit à l'erreur) et pour qui les conditions d'enseignement sont prioritaires ; le fait que les règles de gestion de la classe apparaissent seulement en $9^{\text {ème }}$ position renforce l'impression de dépendance de la bonne disposition des apprenante-s. Le deuxième groupe de critères introduit les spécificités de l'enseignement des LCE telles qu'abordées dans la formation. La prise de responsabilité de la part de l'enseignante et son autonomie dans la prise des décisions d'enseignement sont liées à ces critères. Le critère semblant le moins prioritaire, dans les perceptions des étudiant-e's, touche à l'équilibre des opportunités d'apprentissages et en même temps à la conception de la langue sous-jacente (cf. notre troisième hypothèse). Dans l'ensemble, ces résultats paraissent tout à fait cohérents pour des enseignant·es débutante's et vont dans le sens de l'hypothèse formulée à ce sujet.

37 Si l'on procède à une analyse plus fine des appréciations de priorité, les résultats paraissent relativement hétérogènes, mais ils permettent d'identifier quelques éléments intéressants en réponse à la première question de recherche.

Quatre critères réunissent une majorité de classements dans la fourchette 1 à 4 , «très important »; il s'agit des deux critères de la catégorie 5 « Gestion de la classe et climat de 
classe » $(52,2 \%$ pour le critère 13 et $40 \%$ pour le critère 12$)$, du critère 4 constituant à lui seul la catégorie 2 "Droit à l'erreur » (49,3\%) et du critère 1 "Maîtrise de la langue et engagement pour l'apprentissage des élèves $»^{8}(40,9 \%)$. Les critères 3 (utilisation de la langue enseignée comme moyen de communication principal en classe) et 11 (structuration des leçons) sont considérés comme très importants par plus d'un tiers des étudiante's : $35,8 \%$ pour le critère 3 et $37 \%$ pour le critère 11 .

Les critères de la troisième thématique «Enseignement / apprentissage et rôle des élèves " sont classés comme importants ou moins importants et ne sont donc pas au centre des préoccupations; il en va de même pour les critères 9 et 10 de la catégorie 4 "Types d'activités et structuration des leçons » se référant à des types d'activités d'apprentissage visant à assurer l'équilibre des opportunités d'apprentissage et la consolidation de l'apprentissage.

Pour résumer, par rapport aux trois facteurs : gestion de la classe, gestion des contenus et gestion des langues ; l'analyse globale montre que c'est la gestion de la classe qui parait prioritaire, suivi de la gestion des langues; la gestion des contenus ne vient qu'en dernière position. L'analyse fine donne des résultats plus nuancés mais confirme cette tendance générale.

\section{Classement des critères en fonction des filières : secondaire 1 versus secondaire 2}

\section{Classement des critères de qualité par les étudiant·e·s du secondaire 1 (allemand, anglais et italien)}

Le tableau 3 ci-dessous montre les classements des 35 étudiante-s du secondaire 1 qui ont effectué cette tâche (12 pour l'allemand, 17 pour l'anglais et 6 pour l'italien).

Tableau 3 : Classement des 13 critères, secondaire $1(n=35)$

\begin{tabular}{|c|c|c|c|c|c|c|c|c|c|c|c|c|c|}
\hline \multirow[b]{3}{*}{ Classement } & \multicolumn{13}{|c|}{ Critère en \% } \\
\hline & \multicolumn{3}{|c|}{$\begin{array}{l}\text { Rôle et présence } \\
\text { de la langue- } \\
\text { culture }\end{array}$} & \multirow{2}{*}{\begin{tabular}{|l} 
Droit à \\
l'erreur
\end{tabular}} & \multicolumn{4}{|c|}{$\begin{array}{l}\text { Enseignement } \\
\text { apprentissage et rôle } \\
\text { des apprenant.e's }\end{array}$} & \multicolumn{3}{|c|}{$\begin{array}{l}\text { Types d'activités } \\
\text { et structuration } \\
\text { des leçons }\end{array}$} & \multicolumn{2}{|c|}{$\begin{array}{l}\text { Gestion de } \\
\text { la classe } \\
\text { et climat } \\
\text { de classe }\end{array}$} \\
\hline & 1 & 2 & 3 & & 5 & 6 & 7 & 8 & 9 & 10 & 11 & 12 & 13 \\
\hline 1 à 4 & 33,3 & 15,2 & 26,5 & 63,6 & 27,3 & 31,3 & 24,2 & 26,5 & 20,6 & 15,2 & 39,4 & 45,5 & 55,9 \\
\hline 5 à 9 & 27,3 & 39,4 & 32,4 & 15,2 & 33,3 & 31,3 & 33,3 & 41,2 & 38,2 & 45,5 & 33,3 & 15,2 & 20,6 \\
\hline 10 à 13 & 24,2 & 30,3 & 26,5 & 6,1 & 24,2 & 21,9 & 27,3 & 17,6 & 26,5 & 24,2 & 12,1 & 24,2 & 8,8 \\
\hline 0 & 15,2 & 15,2 & 14,7 & 15,2 & 15,2 & 15,6 & 15,2 & 14,7 & 14,7 & 15,2 & 15,2 & 15,2 & 14,7 \\
\hline
\end{tabular}

Tout d'abord, environ $15 \%$ des étudiant-e's du secondaire 1 considèrent qu'il ne leur est pas possible d'établir une priorisation des critères (classement « 0 »; le pourcentage varie en fonction des totaux valides pour chaque critère).

Les critères privilégiés sont les critères 4 (droit à l'erreur), 13 (climat de classe basé sur la confiance), 12 (gestion de classe avec des règles claires, temps d'apprentissage), suivi du 
critère 11 (structuration des leçons). Concernant le droit à l'erreur, comme il se réfère tant aux apprenant·e's qu'aux enseignant·e's, il est difficile de savoir à qui les étudiant·e's ont pensé en le classant; nous soupçonnons que le droit aux erreurs également pour l'enseignante joue un rôle important pour ce « bon » classement. Pour les critères 1 à 3 se référant à la présence et au rôle de la langue étrangère en classe, nous constatons que ni la maitrise de la langue par l'enseignante, couplée à l'engagement pour les apprentissages des apprenant-e's (critère 1), ni le recours à la langue enseignée comme langue de communication (critère 2) ne sont considérés comme hautement prioritaires par une majorité des étudiante-s; environ un quart des étudiant·es les ont même classés comme (relativement) peu importants. Quant au critère 3 (présence de la dimension (inter-)culturelle et enrichissement par des documents authentiques) qui n'a également recueilli que peu de voix comme étant prioritaire, presque $40 \%$ des étudiante-s le considèrent néanmoins comme important (intervalle 5 à 9). Même en tenant compte du fait que la hiérarchisation des critères de qualité est ressentie comme difficile par les étudiante-s (ce que des commentaires montrent) et que le regroupement par intervalles fait perdre des nuances, ces résultats nous semblent indiquer que ce sont la gestion de la classe et la survie en classe qui constituent une préoccupation plus grande que les aspects concernant l'enseignement de la langue étrangère proprement dit. Les classements relativement bas des critères liés à la langue peuvent également être interprétés dans ce sens : si la gestion de la classe prend beaucoup d'énergie et de temps, cela va souvent de pair avec le recours à la langue de scolarisation. L'enseignante en formation aurait alors un effort conséquent à fournir pour créer les conditions pour l'apprentissage, ce qui empêcherait la gestion de classe dans la langue enseignée (cf. critère 3). Une autre interprétation, complémentaire à la précédente, est en rapport avec la maîtrise de la langue-culture étrangère par les enseignante-es et les apprenante's : il est tout à fait possible que le profil de maitrise de la LCE par les enseignante's ne leur permet pas de gérer l'enseignement majoritairement dans la LCE, ceci éventuellement couplé à un ressenti d'insécurité linguistique (cf. Roussi, 2009). Une autre explication pourrait être liée à la conception des capacités des apprenant·e-s par les enseignant-e·s; en effet, l'idée que les apprenante-s ne comprendraient pas suffisamment la LCE est souvent avancée par les étudiant·ess, par ex. lors de discussions après une visite d'enseignement. Et finalement, l'on peut concevoir que ces classements des étudiantees soient (du moins en partie) le reflet des pratiques d'enseignement observées pendant leur stage dû à l'importance de la formation pratique et à la nécessité pour les étudiant·es d'adapter leur enseignement à la culture de l'établissement pour s'y intégrer.

Les groupes de critères concernant le rôle des apprenantees dans l'enseignement (critères 5 à 8), les types d'activités et la structuration des leçons (critères 9 à 11) en tant que critères de qualité didactique, sont pour la plupart considérés comme appartenant à l'intervalle du milieu, récoltant souvent plus d'adhésion que la maîtrise de la langue. Dans l'ensemble, ces résultats semblent indiquer que les future's enseignante's de LCE au secondaire 1 sont sensibles à ces critères de qualité de l'enseignement des langues, mais que les éléments de nature plutôt pédagogique (gestion de la classe) sont au centre de leur préoccupation. Le résultat le plus frappant nous semble être le peu de priorité accordée à la maîtrise et l'utilisation de la langue étrangère en classe; comme nous l'avons vu, les explications peuvent être multiples et il faudrait investiguer plus en profondeur pour mieux comprendre ces résultats. Dans la mesure où l'on peut considérer la maitrise de «leur » LCE comme une constituante de l'identité professionnelle d'un'e enseignante de LCE, l'idée que la langue-culture soit considérée comme aussi peu 
importante ou prioritaire surprend quelque peu ; cette question mérite alors un effort de compréhension soutenu.

\section{Classement des critères de qualité par les étudiant·e·s du secondaire 2 (allemand, anglais, italien et espagnol)}

Les résultats pour les 34 étudiant·es du secondaire 2 ayant effectué le classement (12 pour l'allemand, 17 pour l'anglais, 3 pour l'italien et 2 pour l'espagnol) sont regroupés dans le tableau 4 ci-dessous.

Tableau 4 : Classement des 13 critères, secondaire $2(n=34)$

\begin{tabular}{|c|c|c|c|c|c|c|c|c|c|c|c|c|c|}
\hline \multirow[b]{3}{*}{ Classement } & \multicolumn{13}{|c|}{ Critère en \% } \\
\hline & \multicolumn{3}{|c|}{$\begin{array}{l}\text { Rôle et présence } \\
\text { de la langue- } \\
\text { culture }\end{array}$} & \multirow{2}{*}{\begin{tabular}{|l} 
Droit à \\
l'erreur
\end{tabular}} & \multicolumn{4}{|c|}{$\begin{array}{l}\text { Enseignement } \\
\text { apprentissage et rôle } \\
\text { des apprenant·ess }\end{array}$} & \multicolumn{3}{|c|}{$\begin{array}{l}\text { Types d'activités } \\
\text { et structuration } \\
\text { des leçons }\end{array}$} & \multicolumn{2}{|c|}{$\begin{array}{l}\text { Gestion de } \\
\text { la classe } \\
\text { et clima } \\
\text { de classe }\end{array}$} \\
\hline & 1 & 2 & 3 & & 5 & 6 & 7 & 8 & 9 & 10 & 11 & 12 & 13 \\
\hline 1 à 4 & 48,5 & 29,0 & 45,5 & 35,3 & 22,6 & 21,9 & 21,2 & 19,4 & 6,7 & 23,3 & 34,4 & 34,4 & 48,5 \\
\hline 5 à 9 & 15,2 & 19,4 & 15,2 & 20,6 & 32,3 & 12,5 & 33,3 & 38,7 & 26,7 & 16,7 & 12,5 & 12,5 & 15,2 \\
\hline 10 à 13 & 6,1 & 19,4 & 9,1 & 14,7 & 12,9 & 3.1 & 15,2 & 9,7 & 33,3 & 26,7 & 21,9 & 21,9 & 6,1 \\
\hline o & 30,3 & 32,3 & 30,3 & 29,4 & 32,3 & 31,3 & 30,3 & 32,3 & 33,3 & 33,3 & 31,3 & 31,3 & 30,3 \\
\hline
\end{tabular}

Pour les formations en didactique des langues-cultures étrangères au postobligatoire, la part d'étudiante's considérant qu'une priorisation des critères n'est pas opportune est d'environ un tiers ; c'est un taux assez important qu'il n'est pas aisé d'expliquer - est-ce que les étudiante's étant en général un peu plus âgée's en raison d'un parcours universitaire plus long auraient une vision plus équilibrée des exigences de l'enseignement? Ou est-ce que le fait que les apprenante's soient plus âgée's (plus matures), et en même temps plus performante-s et en général plus avancéeees dans la langue, ne fait pas ressortir les différents critères de la même manière ? Ou encore, est-ce une solution de facilité pour certain'es étudiante-s leur permettant de contourner la consigne de réflexion? Ces résultats purement chiffrés ne nous permettent pas de trancher.

Toujours est-il que pour le secondaire 2 aussi, il se profile quelques critères ressentis comme prioritaires par une majorité; il s'agit des critères 1 (maîtrise de la langue et engagement pour les apprentissages, 48,5\%), 3 (utilisation de la langue en classe, $45,5 \%$ ) et 13 (climat de confiance, 48,5\%). Dans un deuxième temps suivent les critères 4 (droit à l'erreur, 35,3\%), le critère 11 (structuration des leçons, 34,4\%) et le critère 12 (gestion de classe, 34,4\%). Le critère 2 (contact avec la langue-culture, présence de la dimension (inter)culturelle) est au premier plan pour $29 \%$ des étudiante-s du secondaire 2 ; c'est un taux relativement bas qui pourrait indiquer une conception de l'enseignement / apprentissage de la langue-culture plutôt académique, une influence de la formation pratique ou simplement une priorisation en fonction d'urgences plus pressantes pour ces enseignante's en début de carrière. Signalons toutefois que la formation en didactique 
des LCE met un accent important sur le critère 2 et qu'il s'agit là d'un écart qu'il faut tenter de mieux comprendre.

Les critères liés à la perspective des apprenant-e's (critères 5 à 8 ) et les critères de qualité didactiques au sens étroit (critères 9 à 11) sont peu considérés comme prioritaires, à l'exception du critère 11 ; mais signalons quand même que presque $22 \%$ des étudiantees mettent la structuration des leçons dans l'intervalle 10 à 13 « moins important » même si la formation insiste évidemment sur la nécessité de planifier l'enseignement en fonction d'objectifs bien définis. De nouveau, plusieurs interprétations peuvent être envisagées : une simple surcharge des étudiante-s, une exigence peu ressentie dans la formation pratique, une conception de l'enseignement intuitive et non raisonnée?

\section{Comparaison des classements entre les futur.e.s enseignant $\cdot e \cdot s$ des filières secondaire 1 et secondaire 2}

Pour répondre à la question de recherche concernant d'éventuelles différences entre les classements des étudiante's en didactique des langues-cultures au secondaire 1 et au secondaire 2, nous pouvons constater une tendance à valoriser plus les critères liés à la présence et au rôle de la langue-culture au secondaire 2 (à l'exception du critère 2 qui reste en retrait); ces critères sont plutôt considérés comme «importants » (deuxième intervalle, positions 5 à 9) au secondaire 1 . Concernant les critères 1 et 3 (maîtrise et utilisation de la LCE), nous pouvons supposer que la priorisation plus forte de ces critères par les étudiante's du secondaire 2 peut être liée autant à leur attachement à "leur " langue et discipline qu'à leur maîtrise de la langue-culture concernée ou encore à la possibilité et la nécessité perçue de conduire l'enseignement dans la LCE. Cela correspond à l'hypothèse que nous avons énoncée.

Pour ce qui est des critères à caractère plus pédagogique, relationnel, ils prennent plus d'importance pour les étudiante's du secondaire 1 tout en restant importants pour le secondaire 2. La composition plus hétérogène des classes et l'âge des apprenantees au secondaire $1 \mathrm{y}$ est certainement pour beaucoup. Ce résultat correspond également à l'hypothèse concernant notre deuxième question de recherche.

51 Finalement, on peut globalement dire que les étudiante-s des deux filières accordent une priorité moindre aux critères liés aux apprenant·es et aux types d'activités. Toutefois, il ne faut pas conclure que ces critères ne sont pas considérés comme importants par les étudiante's; en effet, nous pensons que dans beaucoup de cas, le classement est à comprendre comme une priorisation en fonction des urgences de l'enseignement.

\section{Classement des critères en fonction des langues enseignées : allemand versus anglais}

Pour cette analyse, nous nous limitons aux deux langues apprises par tou.te.s les apprenantees à l'école obligatoire en Suisse romande, l'allemand en tant que langue nationale et première langue-culture étrangère apprise en Suisse romande et l'anglais, appris en tant que deuxième langue-culture étrangère. Précisons que l'enseignement de l'allemand a une longue tradition en Suisse romande en tant que première langue étrangère - et langue nationale - apprise par tous les apprenante's dès l'âge de 8 ans environ tandis que la généralisation de l'enseignement de l'anglais et son avancement aux degrés primaires (dès 10 ans) sont beaucoup plus récents. 
53 Afin de vérifier si la conception de l'enseignement d'une langue-culture étrangère diffère entre les futur·e's enseignant·e's d'allemand ou d'anglais', nous ne différencierons pas entre les deux filières de formation secondaire 1 ou 2. Concernant la conception de l'enseignement de l'allemand vs. l'enseignement de l'anglais, il est difficile d'anticiper des tendances; mais précisons ici que l'allemand a un statut particulier en Suisse ayant la réputation d'être difficile et étant la langue de la majorité germanophone en Suisse (phénomène du «Röschtigraben ", indiquant quelques différences culturelles, sociales et politiques). Contrairement à cela, l'anglais est considéré comme langue de communication internationale et souvent liée à des intérêts privés ou à des projets d'avenir professionnel des apprenant·es. Dans ce qui suit, nous analyserons les cinq groupes de critères dans l'ordre.

\section{Classement des critères de qualité par les étudiant·e-s en didactique de l'allemand (secondaire 1 et secondaire 2)}

Les résultats du classement des critères de qualité par les 24 étudiant·e's du secondaire 1 (12 personnes) et 2 (12 personnes) se préparant à l'enseignement de l'allemand et ayant suivi la consigne du travail réflexif sont présentés dans le tableau 5 ci-dessous. Comme mentionné dans la description de la démarche, au vu du petit nombre de cas disponibles, les pourcentages sont à considérer avec précaution.

Tableau 5 : Classement des 13 critères, langue enseignée allemand $(n=24)$

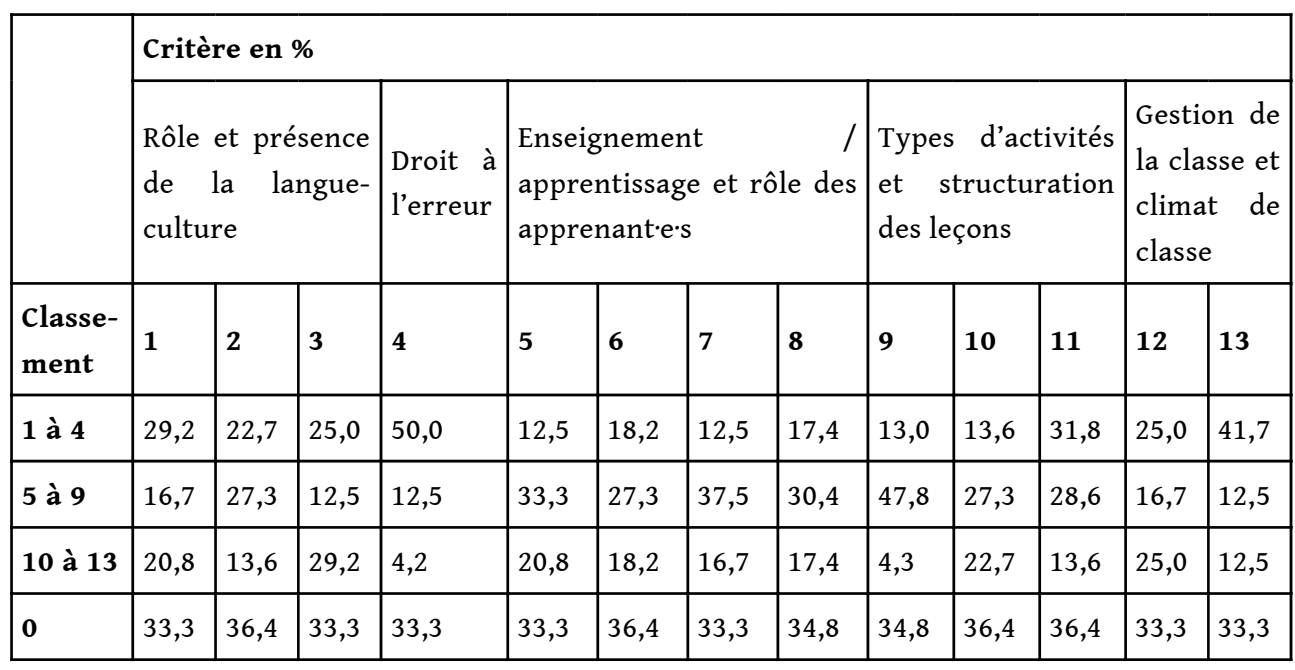

Il s'avère que c'est parmi les future's enseignante's d'allemand que le taux de nonpriorisation des critères (classement $40 »)$ est le plus élevé: environ un tiers des étudiantee's considèrent qu'un classement des critères de qualité, selon leur importance, n'est pas opportun (8 personnes, 7 inscrites en S2, une en S1; les pourcentages exacts varient pour chaque critère en fonction du nombre de données valides). Sept commentaires indiquent que tous les critères ont la même importance (cf. classement général des critères), le huitième signale la difficulté d'effectuer un classement.

Pour ce qui est du premier groupe de critères, "Présence et rôle de la langue-culture ", les étudiant·es en didactique de l'allemand n'accordent pas une haute priorité à ces trois critères qui sont de $29,2 \%$ pour la maîtrise de la langue et l'engagement pour les 
apprentissages, $22,7 \%$ pour les contacts avec la langue-culture et la dimension (inter)culturelle et de $25 \%$ pour l'utilisation de l'allemand comme langue de communication en classe. Si nous complétons ce tableau avec les pourcentages pour les priorités basses, l'impression de peu de priorité accordée à ces critères s'accentue : 20,8\% pour le critère $1,13,6 \%$ pour le critère 2 et $29,2 \%$ pour le critère 3 . Ces résultats sont bien sûr difficiles à interpréter mais ils soulèvent des questions: comment ces futurees enseignant-es d'allemand conçoivent-ils / elles l'apprentissage de cette langue ? Et quels sont leurs objectifs pour cet apprentissage? L'allemand est-il vu comme une langue de communication ou en tout cas par certaine's comme un objet d'étude ? Pensent-elles/ils qu'il faut d'abord « étudier » la langue avant de pouvoir l'utiliser? Est-ce que les future's enseignante's d'allemand ont une maitrise suffisante de la langue-culture leur permettant de l'utiliser aisément en classe? Ou est-ce qu'elles/ils estiment les apprenantees incapables de suivre les leçons en allemand? Pour l'instant, ces questions resteront sans réponse mais elles méritent certainement un approfondissement.

Concernant le critère 4 "Droit à l'erreur ", il figure parmi les critères très importants pour l'allemand, avec l'ambiguïté non résolue par rapport aux auteurees des erreurs : les apprenante's et / ou l'enseignante.

Pour les critères 5 à 8 du troisième groupe « Enseignement / apprentissage et rôle des élèves ", les pourcentages les plus élevés se situent dans le classement de l'intervalle du milieu qui correspond selon le découpage proposé à la valeur « important ». Les critères 9 à 11 du groupe 4 «Types d'activités et structuration des leçons » présentent un tableau plus nuancé : le critère 9 (équilibre entre apprentissage explicite et implicite, limitant notamment le travail de la grammaire) est visiblement important dans le contexte de l'enseignement de l'allemand avec $47,8 \%$ pour l'intervalle du milieu. Le critère 10 touchant aux opportunités de consolidation et d'automatisation n'atteint que $27,3 \%$ au maximum (également dans la catégorie « important »), tandis que pour 22,7\% des future·s enseignante-s d'allemand, il est considéré comme «moins important». Le critère 11, finalement, portant sur la structuration des leçons, est considéré comme très important $(31,8 \%)$ ou important $(28,6 \%)$ par une grande majorité des étudiantees en didactique de l'allemand. Ce résultat n'a cependant pas son correspondant dans le critère 12 , premier critère du cinquième groupe "Gestion de la classe et climat de classe "; la préoccupation de l'utilisation optimale du temps pour l'enseignement en gérant la classe avec des règles claires n'est prioritaire que pour $25 \%$ tandis que $25 \%$ considèrent ce critère comme moins important. Le climat de classe (critère 13), par contre, est très important pour une majorité des futur'e's enseignant·e's d'allemand, à savoir $41,7 \%$.

Pour l'ensemble des étudiantees en didactique de l'allemand, les critères 4, «Droit à l'erreur » et le critère 13 "Climat de confiance » remportent les pourcentages les plus élevés.

\section{Classement des critères de qualité par les étudiant·e.s en didactique de l'anglais (secondaire 1 et secondaire 2)}

60 Les résultats pour les 34 futur·e's enseignant·es d'anglais ayant effectué le classement - 17 étudiante-s du secondaire 1 et 17 étudiante-s du secondaire 2 - sont présentés dans le tableau 6 ci-dessous ; comme mentionné auparavant, les pourcentages sont à considérer avec prudence, à titre indicatif uniquement. 
Tableau 6 : Classement des 13 critères, langue enseignée anglais $(n=34)$

\begin{tabular}{|c|c|c|c|c|c|c|c|c|c|c|c|c|c|}
\hline \multirow[b]{3}{*}{ Classement } & \multicolumn{13}{|c|}{ Critère en \% } \\
\hline & \multicolumn{3}{|c|}{$\begin{array}{l}\text { Rôle et présence } \\
\text { de la langue- } \\
\text { culture }\end{array}$} & \multirow{2}{*}{$\begin{array}{l}\text { Droit à } \\
\text { l'erreur } \\
4\end{array}$} & \multicolumn{4}{|c|}{$\begin{array}{l}\text { Enseignement } \\
\text { apprentissage et rôle } \\
\text { des apprenant·e's }\end{array}$} & \multicolumn{3}{|c|}{$\begin{array}{l}\text { Types d'activités } \\
\text { et structuration } \\
\text { des leçons }\end{array}$} & \multicolumn{2}{|c|}{$\begin{array}{l}\text { Gestion de } \\
\text { la classe } \\
\text { et climat } \\
\text { de classe }\end{array}$} \\
\hline & 1 & 2 & 3 & & 5 & 6 & 7 & 8 & 9 & 10 & 11 & 12 & 13 \\
\hline 1 à 4 & 54,8 & 29,0 & 53,1 & 56,3 & 41,4 & 35,5 & 38,7 & 35,5 & 13,3 & 26,7 & 40,6 & 50,0 & 68,8 \\
\hline 5 à 9 & 29,0 & 38,7 & 31,3 & 21,9 & 34,5 & 48,4 & 25,8 & 45,2 & 26,7 & 40 & 31,3 & 16,7 & 21,9 \\
\hline 10 à 13 & 9,7 & 25,8 & 9,4 & 15,6 & 17,2 & 9,7 & 29,0 & 12,9 & 53,3 & 26,7 & 21,9 & 26,7 & 3,1 \\
\hline 0 & 6,5 & 6,5 & 6,3 & 6,3 & 6,9 & 6,5 & 6,5 & 6,5 & 6,7 & 6,7 & 6,3 & 6,7 & 6,3 \\
\hline
\end{tabular}

61 Le nombre d'étudiante's en didactique de l'anglais n'ayant pas hiérarchisé les critères (classement « $0 »$ ) est réduit; il s'agit de seulement deux personnes argumentant comme leurs collègues en didactique de l'allemand que tous les critères ont une importance égale.

Pour le premier groupe de critères, « Présence et rôle de la langue-culture », les résultats montrent que la maitrise de la langue et l'engagement pour les apprentissages est une préoccupation très importante pour $54,8 \%$ des future's enseignante-es d'anglais et importante pour $29 \%$. Le contact avec l'anglais et la dimension culturelle et interculturelle sont plutôt situés dans l'intervalle du milieu, avec un pourcentage de 38,7 $\%$. Cependant, $29 \%$ considèrent ce critère comme hautement important. L'utilisation de l'anglais comme langue de communication est très importante pour 53,1\% et important pour 31,3\%. Dans l'ensemble, la présence et le rôle de l'anglais sont considérés comme prioritaires par les étudiante's en formation pour l'enseignement de l'anglais.

Le critère 4 , «Droit à l'erreur » est également très important pour une majorité des future's enseignantees d'anglais (56,3\%).

Pour les critères 5 à 8 de la thématique 3 «Enseignement / apprentissage et rôle des élèves ", les critères 5 (différenciation, 41,4\%) et 7 (prise en compte de l'intérêt des

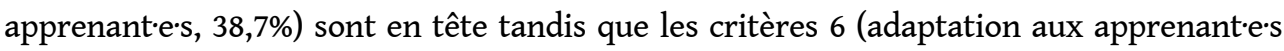
et temps de réflexion) et 8 (élèves en activité et autonomie) sont prioritaires pour plus d'un tiers des étudiante's en didactique de l'anglais (35,5\% pour ces deux critères) et considérés comme importants par $48,4 \%$ pour le critère 6 et $45,2 \%$ pour le critère 8 . Nous relevons des avis partagés pour la prise en compte des intérêts des élèves (critère 7) qui est considéré comme moins important par $29 \%$ des future's enseignante's d'anglais.

Pour la thématique 4 «Types d'activités et structuration des leçons » comprenant les critères 9 à 11, nous pouvons constater d'abord le taux de 53,3\% des étudiante-s considérant l'équilibre entre enseignement implicite et explicite ainsi que la conception large du travail sur les formes comme moins important. La répartition des pourcentages sur les trois intervalles du critère 10 (consolidation, automatisation) $26,7 \%, 40 \%$ et $26,7 \%$ 
semble montrer que les avis sont partagés par rapport à l'importance de ce critère. Le critère 11 au sujet de la structuration des leçons est considéré comme très important par une majorité $(40,6 \%)$, comme important par environ un tiers $(31,3 \%)$ et comme moins important par $21,9 \%$ des future's enseignantees d'anglais.

Les critères 12 et 13 du dernier groupe « Gestion de la classe et climat de classe » figurent parmi les critères les plus souvent considérés comme très importants : $50 \%$ pour le critère 12 (règles claires pour la gestion de classe) et de $68.8 \%$ pour le critère 13 (climat de confiance et humour). Notons toutefois que plus d'un quart des étudiante-s $(26,7 \%)$ considèrent le critère 12 comme moins important.

\section{Comparaison entre les classements des futur.e.s enseignant $e \cdot s$ d'allemand et d'anglais}

67 La troisième de nos questions de recherche concerne les éventuelles différences de classement de priorités entre les future's enseignante's d'allemand et d'anglais. La réponse à cette question est affirmative ; en effet, nous pouvons constater des différences notables pour plusieurs critères, ce qui va dans le sens de l'hypothèse énoncée à ce sujet.

Tout d'abord, le nombre d'étudiant'e's jugeant que les critères sont d'importance égale et ne les hiérarchisant pas est nettement plus élevé parmi les étudiante's en didactique de l'allemand (notamment pour le secondaire 2) qu'en didactique de l'anglais.

69 La deuxième différence concerne le groupe " Présence et rôle de la langue-culture » : dans l'ensemble, la maîtrise de la langue et l'engagement pour les apprentissages des apprenantees (critère 1) ainsi que l'utilisation de la langue enseignée pour la communication en classe (critère 3) sont nettement plus prioritaires pour les étudiante's en didactique de l'anglais que pour leurs collègues d'allemand. Il est évident que ces pourcentages ne permettent pas de se prononcer sur l'utilisation réelle de l'anglais ou de l'allemand dans les pratiques d'enseignement des étudiante-s. Mais ils laissent penser que l'anglais est plus conçu comme une langue de communication, un savoir-faire tandis que l'allemand pourrait être plutôt conçu comme un objet d'enseignement, une langue qu'il faut mettre à distance et aborder dans une perspective « méta » afin de la maîtriser.

Une troisième différence se situe au niveau du troisième groupe de critères « Enseignement / apprentissage et rôle des élèves »; dans l'ensemble, les étudiant·e's en didactique de l'allemand y accordent moins d'importance que leurs collègues d'anglais. On pourrait prudemment avancer l'hypothèse que les future's enseignante-s d'allemand sont plus centrée'es sur l'enseignante et / ou sur l'objet d'enseignement alors que les future's enseignante's d'anglais semblent être plus enclins à prendre en compte la perspective des apprenante-s.

71 Pour le groupe de critères 4 " Types d'activités et structuration des leçons », on voit que les future's enseignante-s d'allemand sont apparemment plus sensibles à la nécessité d'équilibrer les opportunités pour l'apprentissage implicite et explicite et un travail sur les formes au sens large ; il pourrait s'agir d'un effet de formation contrebalançant une tendance à donner beaucoup de poids à l'enseignement grammatical. Cela correspond tant aux traditions d'enseignement observées qu'à la perception de l'allemand comme langue « difficile ». Pour les future's enseignante's d'anglais par contre, cet aspect n'est visiblement pas prioritaire et ceci est tout à fait cohérent si l'on prend en considération leur position par rapport à la présence et le rôle de la langue dans l'enseignement. Le critère 10 portant sur la nécessité d'entraîner les apprentissages pour les stabiliser, voire 
les automatiser est considéré comme plus important par les future.s. enseignante-s d'anglais ( $26,7 \%$ «très important ", $40 \%$ « important ", vs. $13,7 \%$ «très important » et $27,3 \%$ « important » pour l'allemand). Cette différence pourrait indiquer encore une fois une conception dominante de l'anglais comme un savoir-faire qu'il convient d'utiliser régulièrement et entraîner tandis que l'allemand pourrait être perçu comme un savoir explicite à utiliser de manière contrôlée, un entraînement ne serait alors pas indiqué. Mais il est évident que ce ne sont que des explications hypothétiques, basées en partie sur notre expérience de formation. Le dernier critère dans ce groupe est le critère 11 décrivant la cohérence de la structuration des leçons. Là aussi, l'on constate une légère asymétrie entre les priorités des étudiant·e's en didactique des deux langues : les future's enseignante:s d'anglais sont légèrement plus attachée's à la structuration des leçons $(40,6 \%$ « très important » et $31,3 \%$ « important ») que leurs collègues d'allemand $(31,8 \%$ « très important », $28,6 \%$ « important »).

Cette différence se trouve aussi dans le dernier groupe de critères « Gestion de classe et climat de classe ». Tant le critère 12 (règles claires pour la gestion de la classe) que le critère 13 (climat de confiance) sont considérés comme prioritaires par une grande majorité des étudiante's d'anglais ( $50 \%$ « très important » pour le critère 12 et $68,8 \%$ pour le critère 13). Quant aux future's enseignante-s d'allemand, ils sont beaucoup moins convaincue's de la priorité d'une gestion de classe basée sur les règles claires (25\%) et accordent également moins de priorité au climat de confiance dans la classe (41,7\%).

Les différences que nous avons pu identifier entre les classements de critères des future-s enseignante'e-s d'allemand $v s$. d'anglais paraissent systématiques et cohérentes ; on peut y voir l'expression d'une conception différente de l'enseignement / apprentissage d'une langue-culture étrangère que nous avons caractérisée comme mettant l'accent sur le côté explicite et plutôt centré sur l'enseignante pour l'allemand vs. une approche privilégiant plus un apprentissage implicite et plutôt centré sur les apprenante's pour l'anglais. Toutefois, ces tendances ne concernent pas tous les étudiante's ni en didactique de l'allemand ni en didactique de l'anglais. En effet, un tiers environ des future's enseignante's d'allemand sont d'avis que tous les critères sont d'importance égale, ce qui suggère une perception globale des enjeux d'un enseignement de langues-cultures de qualité et présuppose une certaine expérience.

\section{Discussion et conclusion}

\section{Limites de la démarche}

Tout d'abord, rappelons une dernière fois que ces analyses ont une base empirique limitée et ne peuvent en aucun cas être généralisées même si elles paraissent confirmer des intuitions reposant sur une longue expérience dans la formation en didactique des langues-cultures. A cela s'ajoutent toutes les sources de biais que nous avons énumérées à la fin de la présentation de la problématique. De plus, nous manquons d'informations cruciales pour mieux situer les résultats. En effet, comme nous l'avons mentionné à plusieurs endroits, en dehors des didactiques des différentes LCE et des deux filières de formation du secondaire, les étudiante's ne constituent de loin pas un groupe homogène. Nous n'avons pas pu prendre en considération ni le statut de la langue-culture dans le répertoire plurilingue des étudiante's (langue première, langue acquise plutôt en contexte naturel ou plutôt en contexte formel, etc.) ni l'expérience d'enseignement 
préalable des enseignante's ni encore leur parcours d'apprentissage langagier, le contexte de leur stage, leur expérience de vie générale ou encore leur style cognitif pour nommer quelques facteurs susceptibles d'influencer leur conception de l'enseignement. Il faut également préciser que les enseignante's en formation ne sont pas tou'te's des débutante's dans la mesure où il peut s'agir d'un complément dans le cadre de la reconnaissance d'une formation accomplie à l'étranger, d'une formation pour une discipline additionnelle ou encore une formation pour régulariser une activité d'enseignement sans les titres requis.

Concernant le traitement des données, nous n'avons pas croisé les différents résultats afin de les analyser de manière plus fine.

Il ne faut pas non plus surinterpréter ces classements donnant suite à une consigne contraignante que la plupart des étudiante-s a soigneusement respectée ; la difficulté de faire un tel choix de priorités a été signalée plusieurs fois. A cela s'ajoute le fait que les conditions de stage liées aux deux modalités possibles (stage effectué en responsabilité ou dans une classe tenue par un enseignante responsable de la formation pratique) font que les expériences et pratiques d'enseignement des étudiant-ess peuvent être fort diverses : d'une pratique tout à fait autonome à une pratique guidée, voire imposée dans des classes dont les étudiant·e's ne connaissent pas forcément bien les apprenant·es, n'y intervenant que sporadiquement. En stage à responsabilité par contre, les jeunes enseignantees peuvent être confrontée's à des apprenante's ou des classes difficiles ne leur permettant guère d'expérimenter les démarches et techniques didactiques proposées dans la formation de manière sereine, tandis que leurs collègues en stage accompagné n'ont pas beaucoup d'occasions de se confronter aux difficultés que peut poser la dimension pédagogique de la profession.

\section{Discussion des résultats}

Malgré ces restrictions, les résultats globaux nous permettent de confirmer les priorités auxquelles l'on peut s'attendre de la part d'enseignanteees en fin de formation ou en début de carrière; si l'on se réfère au classement général que nous avons présenté pour répondre à notre première question de recherche, la plus grande importance revient à assurer un minimum de survie en classe. En deuxième place, les étudiante-s placent un leadership structurant et organisationnel ainsi que le suivi des apprentissages des apprenante-s et leur implication en ce qui concerne leurs intérêts. En troisième lieu seulement viennent les réglages fins au niveau de la didactique et de la méthodologie. Ces tendances générales nous paraissent aussi lucides que cohérentes et se confirment à certains moments par une analyse plus fine. Si les contenus de formation en didactique viennent seulement "après ", cela ne veut bien sûr pas dire que les étudiant·e's ne sont pas consciente's de l'importance de ces éléments. Dans l'ensemble, nous pensons que les résultats illustrent bien la complexité d'assumer l'enseignement d'une LCE en début de carrière et la perception nuancée et réaliste des priorités d'un groupe d'enseignante-s en début de carrière devant dans un premier temps « faire leur place » dans cette profession.

Concernant la deuxième question de recherche par rapport aux différences entre étudiante's de la filière du secondaire 1 et étudiantees de la filière du secondaire 2 , la majeure différence consiste en une attention plus grande accordée à la maîtrise de la langue et à l'utilisation de la langue enseignée en classe au secondaire 2, conformément à leur formation en langue-culture plus exigeante et au niveau en général plus avancé de 
leurs apprenante-s. Tout comme pour leurs collègues du secondaire 1, la priorité accordée à la perspective de l'apprenante et aux dimensions didactiques proprement dites est moindre. Cela illustre bien encore une fois que les préoccupations d'une grande partie des enseignante'e's en formation sont centrée's sur la perspective de l'enseignante et qu'ils / elles n'arriveraient pas encore à prendre en compte la complexité de la situation d'enseignement dans son ensemble. En cela, ces résultats sont tout à fait compatibles avec les phases de la profession enseignante décrite par Huberman (1989) qui caractérise la première phase comme une phase de tâtonnement voire de survie. Plus près de la didactique des langues-cultures, Causa (2012) décrit toute la complexité du répertoire didactique d'une enseignantee et son développement. Nous pouvons penser que dans un premier temps, les enseignant-e's débutante-s se basent en grande partie sur des éléments ressentis comme sûrs (car connus) et supposés correspondre aux attentes des apprenante's, de leurs collègues, des parents d'élèves, etc.

Mais c'est la troisième question de recherche portant sur les différences entre les future's enseignante's d'allemand vs. d'anglais qui donne les résultats les plus intéressants. En effet, l'allemand a un statut particulier en Suisse romande et notamment dans le canton de Vaud, à la fois en tant que langue nationale pas toujours appréciée pour des raisons historiques et encore largement accompagnée de la réputation d'être une langue difficile et certes utile, mais peu attrayante. La comparaison des classements prioritaires des étudiante's en didactique de ces deux langues semble confirmer que les perceptions de ces deux langues et de leur enseignement / apprentissage diffèrent toujours en défaveur de l'allemand. Il est évident que nos résultats ne peuvent que suggérer des tendances. De plus, nous n'avons pris en considération que la perspective de l'enseignante ; il y a en effet fort à parier que le statut différent de l'allemand vs. l'anglais évoqué se manifeste également à travers les attentes, les attitudes et le comportement des apprenante-s et qu'il pourrait être simplement plus «facile » d'enseigner l'anglais en Suisse romande que l'allemand. Néanmoins, ces données confirment une intuition et nous pensons qu'ils nous poussent à investiguer plus en profondeur le rapport des étudiantees en didactique des langues à « leurs » langues-cultures afin de les aider à développer l'enseignement le plus efficace possible au niveau des apprentissages et de la motivation de leurs apprenante's.s.

\section{Mise en perspective et conclusion}

Comme souvent dans ce type de recherche, les résultats semblent simplement confirmer le sens commun et l'intuition de la formatrice-chercheure auteure de ce texte. Mais à travers une démarche de recherche, la pensée est pour ainsi dire auscultée, mise en doute, explicitée, étayée. Malgré le fait que des résultats de recherche qualitative ne sont ni représentatifs ni généralisables, nous pouvons affirmer que nos constats concernant la préoccupation particulière avec la gestion de classe par exemple, convergeraient avec des recherches effectuées un peu partout dans le monde: Canada (Martineau, Gauthier \& Desbiens, 1999), Turquie (Griffiths, 2012), Asie (Farrell, 2009). Il est évident que les enseignante:s en formation et notamment dans la situation de stage en responsabilité peuvent se sentir tiraillée's entre les demandes de la formation en institution, de leurs maîtres de stage, de leurs collègues, de la classe ; souvent, la première confrontation avec la réalité de la pratique autonome est vécue comme un choc (cf. Farrell, 2009 et Huberman, 1989). 
81 On peut oser une analogie avec des processus d'apprentissage, et postuler que pour les étudiant·es en fin de formation, les démarches didactiques abordées durant la formation se situent en bonne partie dans la zone proximale de développement : dans des conditions contrôlées et sûres, l'étudiant·e peut montrer qu'elle/il maîtrise certaines démarches et en comprend les enjeux. Mais en règle générale, dans la complexité et la surcharge des débuts dans la pratique autonome de l'enseignement, les aspects didactiques émergeront quand une certaine assurance sera acquise, pourvu que durant la formation, la graine de la pratique réflexive et de la pertinence des apports théoriques et scientifiques ait été semée.

Les priorités énoncées par les étudiant·e's du secondaire que nous avons examinées dans ce travail nous semblent correspondre à une représentation lucide de leur situation ; l'apport de la formation en didactique nous paraît bien présent dans la mesure où les étudiant·e's ne rejettent pas les critères ni apparemment l'idée d'un enseignement de qualité ; un certain nombre parmi elles/ils reconnaissent l'interdépendance des critères de qualité. Nous avons donc de bonnes raisons de croire que ces enseignant·e-s arriveront à prendre pleinement en compte la perspective de l'apprenantee et reviendront aux apports de la formation une fois que les routines de base seront mises en place (cf. Farrell, 2009 qui décrit cette évolution).

Toutefois, Tsui (2009) nous met en garde en expliquant que la seule routine et l'expérience ne suffit pas pour assurer un enseignement de langue-culture de qualité ; en effet, pour développer de l'expertise dans l'enseignement, il faut rester dans une dynamique de mise en question, de recherche, de réflexion. La pratique réflexive reste donc d'actualité pour éviter de se figer dans une pratique expérimentée mais nonexperte.

Pour finir, tant notre approche intégrative de la formation en didactique des languescultures étrangères réunissant les futur·e's enseignant·e's de toutes les langues dans certains cours que notre intérêt pour les représentations des enseignant·es nous ont permis d'entrevoir une différence concernant la conception de l'enseignement / apprentissage de l'allemand vs. l'anglais. En effet, les futur·e's enseignant·e's d'allemand semblent plutôt concevoir la langue enseignée comme un objet d'étude à mettre à distance et à comprendre avant de l'utiliser tandis que leurs collègues d'anglais semblent plutôt pencher pour un apprentissage en utilisant la langue dès le départ. Bien sûr, à ce stade, ce ne sont que des suppositions peu étayées mais qui correspondent bien aux observations et aux échanges entre représentant·es des différentes didactiques. Ces hypothèses nous incitent à chercher à mieux comprendre encore les conceptions des enseignant·e's (cf. Barcelos, 2014), pour pouvoir les thématiser lors de la formation. En effet, dans une conception intégrative de la formation à l'enseignement des LCE, comme elle est pratiquée à la HEP VD, il est important d'être attentif à de telles différences pour inciter les étudiant·e's à expliciter leurs représentations et éventuellement les réviser. En même temps, cela nous invite à élaborer des tâches de réflexion obligeant les étudiant·ess à échanger avec des collègues se préparant à l'enseignement d'une autre LCE dans une autre filière. A côté de cela, l'on peut envisager d'élargir les modèles d'enseignement vécus par les étudiant·e's en leur proposant d'assister à des cours de langue-culture mettant en œuvre les approches abordées durant leur formation en didactique ; au niveau de leur parcours d'apprentissage personnel, un travail de biographie langagière et culturelle portant en particulier sur les modalités d'apprentissage et leur efficacité ressentie peut s'ajouter au travail réflexif. De cette façon, nous pouvons espérer mettre 
en place l'approche intégrative de l'enseignement des LCE au service du plurilinguisme des apprenante's.

\section{BIBLIOGRAPHIE}

Altet, M. (2001). « Les compétences de l'enseignant-professionnel: entre savoirs, schèmes d'action et adaptation, le savoir analyser ». In Paquay. L., Altet, M., Charlier, E. \& Perrenoud, Ph. (dir.), Former des enseignants professionnels. Quelles stratégies? Quelles compétences? 3e édition. Bruxelles : De Boeck Université. pp. 27-40.

Barcelos, A. M. F. (2014). « Les croyances des enseignants de langue: une clé pour comprendre leurs pratiques ». Le français dans le monde. Recherches et applications (56). pp 64-82.

Beacco, J.-C. (2007). L'approche par compétences dans l'enseignement des langues. Paris : Didier.

Borg, S. (2006). Teacher Cognition and Language Education. London, New York : Continuum.

Cambra Giné, M. (2003). Une approche ethnographique de la classe de langue. Paris : Didier.

Carter, K. \& Doyle, W. (1987). Teachers knowledge structures and comprehension processes. In J. Calderhead (dir.), Exploring teachers thinking. Londres : Cassell. pp. 147-160)

Causa, M. (2012). « Le répertoire didactique : une notion complexe ». In Causa, M. (dir.), Formation initiale et profils d'enseignants de langues. Enjeux et questionnements. Bruxelles : De Boeck. pp. 15-72.

Cicurel, F. (2014). « Pensée en action / pensée sur l'action: une fenêtre sur l'agir professoral? » Le français dans le monde. Recherches et applications (56). pp 83-100.

Coll. (2001). Cadre européen commun de référence pour les langues. Apprendre, enseigner, évaluer. Strasbourg : Conseil de l'Europe, Division des langues vivantes.

Farrell, T. S. C. (2009). « The Novice Teacher Experience ». In Burns, A. \& Richards, J. C. (dir.), The Cambridge Guide to Second Language Teacher Education. Cambridge, New York etc.: Cambridge University Press. pp. 182-189.

Griffiths, C. (2012). « Focus on the teacher ». ELT Journal, 66(4). pp 468-476.

Hall, G. \& Cook, G. (2012). « Own-language use in language teaching and learning ». Language Teaching, 45(03). pp 271-308.

Hattie, J. (2009). Visible Learning. A synthesis of over 800 meta-analyses relating to achievement. London \& New York: Routledge (Kindle Edition).

Hattie, J. (2012). Visible Learning for Teachers. Maximizing Impact on Learning. London \& New York: Routledge.

Huberman, M. (1989). « Les phases de la carrière enseignante ». Revue française de pédagogie, 86(1). pp 5-16.

Levine, G. S. (2011). Code Choice in the Language Classroom. Bristol UK : Multilingual Matters.

Littlewood, W. (2014). « Communication-oriented language teaching: Where are we now? Where do we go from here? ». Language Teaching, 47(03). pp 349-362. 
Lortie, D. C. (1975, new preface 2002). Schoolteacher. With a New Preface. Second Edition. Chicago, London: The University of Chicago Press.

Martineau, S., Gauthier, C. \& Desbiens, J.-F. (1999). « La gestion de classe au cœur de l'effet enseignant ». Revue des sciences de l'éducation, 25(3). pp 467-496.

Muller, F. (2008). Manuel de survie à l'usage de l'enseignant (même débutant). 3e édition revue et augmentée. Paris : L'étudiant.

Richoz, J.-C. (2009). Gestion de classes et d'élèves difficiles. Des exemples concrets et des méthodes d'intervention efficaces pour prévenir et résoudre les problèmes de discipline à l'école. Lausanne : Favre.

Roussi, M. (2009). L'insécurité linguistique des professeurs de langues étrangères non natifs: le cas des professeurs de grec de français. Doctorat en didactique des langues et des cultures, Université Sorbonne Nouvelle - Paris 3, Paris. Disponible en ligne: https://tel.archives-ouvertes.fr/ tel-00787305/document

Starkey-Perret, R. (2013). « Représentations des enseignants sur leur métier et acquisition de L2 de la part des apprenants: quels liens peuvent être établis? ». Recherches en didactique des langues et des cultures: Les Cahiers de l'Acedle, 10(1 - Apprendre les langues autrement). pp 177-200.

Tsui, A. B. M. (2009). « Teaching Expertise: Approaches, Perspectives, and Characterizations ». In Burns, A. \& Richards, J. C. (dir.), The Cambridge Guide to Second Language Teacher Education. Cambridge, New York: Cambridge University Press. pp. 190-197.

Wokusch, S. \& Sieber, J. (2000). Profession: Enseignant(e) de langue. Représentations, aspects théoriques, formation. Lausanne : CVRP.

Wokusch, S. (2013). «Qu'est-ce qu'un bon enseignement des langues étrangères? Conceptions scientifiques et conceptions d'enseignant-e-s ». Babylonia (01). pp 57-63.

Wokusch, S., Thonhauser, I., \& Zappatore, D. (2015). Concept de formation à l'enseignement des langues et cultures étrangères. Lausanne. Disponible en ligne: https://www.hepl.ch/files/live/sites/ systemsite/files/uer-lc/concept-formation-uerlc-2015-hep-vaud.pdf

Woods, D. (1996). Teacher Cognition in Language Teaching. Beliefs, decision-making and classroom practice. Cambridge, UK: Cambridge University Press.

Woods, D. \& Knoerr, H. (2014). « Repenser la pensée enseignante ». Recherches et applications. Le français dans le monde (56). pp. 16-32.

\section{NOTES}

1. Un très grand merci à mes collègues Ingo Thonhauser et Luc Fivaz pour leur relecture attentive et constructive.

2. Enquête non publiée mais dont les résultats ont été intégrés dans l'élaboration du concept de formation en didactique des langues-cultures étrangères à la HEP VD avec la collaboration d'I. Thonhauser et D. Zappatore, 2015.

3. La formation en didactique consiste en deux modules dotés de 6 crédits chacun. Chaque module comprend un cours, commun à toutes les didactiques des LCE, et des séminaires, spécifiques à chaque didactique et chaque filière de formation (secondaire 1 ou 2). Le cours du premier module réunit les deux filières, tandis que le cours du second module est donné séparément pour chaque filière mais avec des contenus analogues.

4. Alternance codique : cf. par exemple Cambra Giné (2003, chap. 4.2), l'article State of the art de Hall et Cook (2012) et la monographie de Levine (2011). 
5. Il s'agit encore de niveaux généraux et non spécifiques à la profession; signalons également qu'un certain nombre d'étudiant·es des deux filières se préparent à enseigner leur première langue (langue "maternelle").

6. Sans oublier que l'enseignement postobligatoire comprend l'enseignement professionnel; pour certaines filières de formation, le niveau de compétence n'est pas beaucoup plus élevé qu'au secondaire 1. L'enseignement professionnel connaît aussi une importante hétérogénéité concernant les compétences des élèves.

7. La culture d'enseignement locale est familière à l'auteure pour avoir enseigné l'allemand aux degrés du secondaire durant une quinzaine d'années et ensuite à travers son activité dans la formation des enseignant.e's de LCE.

8. Pour ce critère contenant une double affirmation, il est probable que ce soit la première affirmation, à savoir la maîtrise de la langue enseignée par l'enseignant·e, qui ait retenu l'attention des étudiant·es. Les critères n'ayant pas été formulés pour en faire une étude scientifique, nous ne pouvons pas lever cette ambiguïté.

9. C'est sans compter le fait que certain'e's enseignant'e's se forment dans deux langues ; c'est une constellation toutefois relativement rare. Rappelons encore une fois que ces résultats ne peuvent pas être généralisés à toutes les promotions d'étudiant·e·s.

\section{RÉSUMÉS}

Comment la formation en didactique est-elle reçue par les futur'e's enseignant·e's de languescultures étrangères? Quelles sont les priorités retenues par les enseignant·es novices pour développer un enseignement de qualité? Notre recherche aborde cette question à travers l'analyse d'un travail de réflexion en fin d'études, demandant aux étudiant·e's de hiérarchiser 13 critères de qualité selon leur priorité pour leur futur enseignement; elle se situe ainsi dans le champ de la pensée enseignante ou «teacher cognition». Ces indicateurs de qualité touchent aux domaines de la présence et du rôle de la langue-culture enseignée en classe, le droit à l'erreur, l'enseignement / apprentissage et le rôle des apprenant·e's, les types d'activités et structuration de leçons, la gestion de la classe ainsi que le climat de classe ; l'enseignement est donc pris en compte dans sa globalité. Un des enjeux est la conception intégrative de la formation en didactique dans notre institution, réunissant pour certains cours communs les étudiant·es de toutes les didactiques des langues-cultures vivantes (allemand, anglais, italien, espagnol) et des deux filières de l'enseignement secondaire (apprenante-s de 12 - 15 ans env. pour le secondaire 1 et apprenant·es de 16 - 19 ans env. pour le secondaire 2). Nous nous interrogerons en particulier sur les éventuelles différences entre ces catégories d'étudiant·es afin de pouvoir réguler la formation en didactique en fonction de ces résultats.

How do pre-service teachers react to the contents and principles of language pedagogy they are exposed to during their training? Which aspects do novice language teachers prioritize in order to develop quality in their teaching? This empirical study is based on a framework of 13 quality criteria for language teaching developed by the author; a reflexive task asking pre-service secondary language teachers at the end of their training to prioritize the criteria constitutes the corpus of this study in pre-service teacher cognition. The quality indicators pertain to the following dimensions of language teaching considered in an encompassing perspective: the functions and use of the foreign language in the classroom, the right to errors and mistakes, the 
role of students in the teaching / learning process, activity types and lesson structure, classroom management and climate. The integrative concept of language teacher training in our institution is also an important issue: for part of their training, students of lower and upper secondary level of all four foreign languages (English, German, Italien, Spanish) attend the same courses about general theoretical aspects of language pedagogy relevant to all languages and learners. Differences between lower and upper secondary pre-service teachers as well as differences between teachers of different languages (especially German vs. English) are an important research interest, as they are important for the fine-tuning of course contents.

\section{INDEX}

Thèmes : Varia

Keywords : quality of language teaching, teacher cognition, integrative approach to language pedagogy, novice teachers

Mots-clés : qualité de l'enseignement des langues-cultures, pensée enseignante, approche intégrative de la didactique des langues-cultures étrangères, enseignant·e·s novices

\section{AUTEUR}

\section{SUSANNE WOKUSCH}

Susanne Wokusch est professeure en Didactique des langues-cultures étrangères à l'Unité d'enseignement et de recherche Didactiques des langues et cultures de la Haute École Pédagogique du Canton de Vaud (HEP VD) ; elle intervient notamment dans la formation à l'enseignement des langues étrangères dans les filières du secondaire. Ses intérêts de recherche portent sur la pensée enseignante, la formation à l'enseignement des langues-cultures et la didactique intégrative.

Courriel : susanne.wokusch [at] hepl.ch

Toile : https://hepl.academia.edu/SusanneWokusch

Adresse : UER Didactiques des langues et cultures, HEP VD, Avenue de Cour 25, CH-1014

Lausanne, Suisse. 